\title{
Pasak estetik dari bahan fiber reinforced composite Esthetic post made of fiber reinforced composite materials
}

\author{
${ }^{1}$ Emy Ardana, ${ }^{2}$ Aries Chandra Trilaksana \\ ${ }^{1}$ PPDGS Konservasi Gigi \\ ${ }^{2}$ Bagian Konservasi \\ Fakultas Kedokteran Gigi Universitas Hasanuddin \\ Makassar, Indonesia
}

\section{ABSTRACT}

The prosthetic treatment of seriously damaged teeth after treated with endodontic often require an endodontic post as an additional retention element for core build-up prior to crown restoration. In addition to metal-based posts and zirconia-based ceramic posts, fiber reinforced composite (FRC) post system has become to be widely used in the restoration of endodontically treated teeth. A FRC post offers a number of advantages over a metal post due to its modulus of elasticity being closer to that of dentin and superior esthetic quality. Teeth restored with FRC posts show better resistance to fracture propagation than teeth restored with prefabricated or cast metal posts. Endodontically treated teeth reinforced with a prefabricated fiber post have shown lower incidences of root fracture.

Key words: fiber reinforced composite, fracture strength

\begin{abstract}
ABSTRAK
Perawatan prostetik dari kerusakan gigi yang telah dirawat endodontik seringkali membutuhkan pasak sebagai tambahan retensi untuk membangun restorasi mahkota. Selain pasak berbasis metal dan zirkonia berbasis keramik, penggunaan sistem fiber reinforced composite (FRC) juga telah digunakan secara luas pada restorasi gigi pasca perawatan endodontik. Pasak FRC memberikan sejumlah keuntungan dibandingkan dengan pasak metal, yaitu pada modulus elastisitas yang dimilikinya untuk melindungi dentin serta kualitas estetik yang dihasilkan relatif lebih baik. Gigi yang direstorasi dengan FRC menunjukkan resistensi yang lebih baik terhadap fraktur dibandingkan dengan gigi yang direstorasi dengan pasak sediaan ataupun pasak metal. Perawatan endodontik gigi dengan menggunakan FRC menunjukkan insidensi yang lebih rendah terhadap terjadinya fraktur akar.
\end{abstract}

Key words: fiber reinforced composite, fracture strength

Koresponden: Emy Ardana, Budi Daya Permai Blok J No 8, Makassar, Indonesia. E-mail: emypomalaa@gmail.com

\section{PENDAHULUAN}

Perawatan endodontik dapat melemahkan gigi, akibat menurunnya jumlah cairan serta hilangnya struktur dentin, ${ }^{1}$ dan bermanifestasi peningkatan risiko terjadinya fraktur.Dengan penambahan pasak endodontik, dapat mengimbangi kelemahan itu. ${ }^{1,2}$ Restorasi gigi non vital seringkali dihubungkan dengan kombinasi dari pasak sediaan atau pasak dan core metal individual serta full crown. ${ }^{2}$ Awalnya, dengan cara ini sebagian besar struktur mahkota dan akar gigi dikorbankan sehingga meningkatkan risiko perforasi akar atau fraktur, pengobatan yang relatif mahal dan lama. ${ }^{3}$ Selanjutnya dikenal totaletch adhesive system dan perbaikan sifat fisik dan mekanik dari resin bonded composite (RBC)., ${ }^{2,4}$ Restorasi adesif memungkinkan klinisi melakukan preparasi gigi seminimal mungkin sehingga dapat mempertahankan struktur jaringan yang sehat. ${ }^{2-6}$

Pasak fiber sewarna gigi diperkenalkan pertama kali pada tahun 1990-an.Dibandingkan pasak metal, memiliki beberapa keuntungan, diantaranya bersifat estetis, berikatan pada gigi, modulus elastisitasnya hampir sama dengan dentin, namun memerlukan preparasi dentin dalam saluran akar., ${ }^{2,4}$
Akhir-akhirini,sistem FRC telah diperkenalkan untuk meningkatkan daya tahan terhadap resin bonded composite (RBC). Ultra high molecular weight polyethylene (UHMWP) yang populer dan dapat diaplikasi klinis diantaranya dapat digunakan sebagai splint periodontal, atau orthodontic retainer, GTJ sementara tanpa logam, dan perawatan sindroma split-tooth. ${ }^{2,48}$ Bahan ini dapat digunakan untuk membangun pasak dan core karena dapat beradaptasi dengan dinding saluran akar tanpa memperluas saluran akar setelah perawatan endodontik. FRC memiliki modulus elastisitas yang hampir sama dengan dentin sehingga tercipta suatu monoblock dentin-post-core system yang dapat mendistribusikan tekanan yang lebih merata ke sepanjang saluran akar. ${ }^{2,4,9}$

Indikasi dari pasak endodontik adalah untuk mendapatkan retensi yang baik dengan pengambilan jaringan sehat seminimal mungkin. Pada beberapa kasus yang tidak didukung jaringan mahkota yang memadai, diperlukan pasak endodontik sebagai tambahan retensi. ${ }^{2,10-12}$

Syarat pasak endodontik adalah high tensile strength, high fatigue resistance dari arah oklusal 
dan shear loading, serta stress-free distribution yang dapat mempengaruhi saluran akar. ${ }^{13-16}$ Perawatan estetik untuk pasak endodontik ini adalah dengan menggunakan mahkota full-ceramic dan gigitiruan jembatan (GTJ) porselin yang berwarna translusen khususnya pada gigi anterior dan premolar. Hal tersebut sebanding dengan warna yang dihasilkan pasak FRC yang warnanya lebih alami sesuai dengan sifat fisiknya.Sifat fisik pasak FRC adalah estetiknya lebih baik pada perawatan saluran akar dibanding logam atau pasak carbon fiber, mudah dilakukan perawatan ulang, penempatan pada tepi restorasi dapat melindungi dari mikroleakage serta bersifat non-galvanic/dan tidak bersifat korosif. Selain itu, pin metal bentuk screw thread dan pasak metal yang pasif memiliki modulus elastisitas yang relatif tinggi, disbanding pasak FRC yang hampir sampa dengan dentin. ${ }^{4-9,17}$

\section{TINJAUAN PUSTAKA}

Pasak FRC terdiri dari resin matriks dalam suatu struktur fiber karbon atau quartz/glass yang diperkuat. ${ }^{4-9,18}$ Pasak FRC sediaan terdiri dari bahan fiber, matriks, dan isi dari fiber yang digunakan dengan volume persentase dari fiber reinforced dalam matriks polimer yang telah dipolimerisasi. Pasak fiber sediaan terdiri dari karbon atau glass (E-glass, S-glass, quartz/silica) fibers, sedangkan matriks yang digunakan biasanya polimer epoxy atau campuran epoxy dan resin dimethacrylate. ${ }^{4}$ Pasak endodontik sediaan yang terbuat dari fiber quartz atau glass FRC mempunyai sifat biomekanik yang baik. ${ }^{4,19}$

Beberapa keuntungan penggunaan FRC secara umum adalah modulus elastisitasnya ${ }^{16}$ yang hampir sama dengan dentin, berkisar $20 \mathrm{GPa}$ dibandingkan dengan pasak logam, core dan mahkota, memiliki flexural strength yang lebih baik dari bahan lain, ${ }^{20-}$ ${ }^{22}$ atraumatik, sangat retentif, resistensinya terhadap

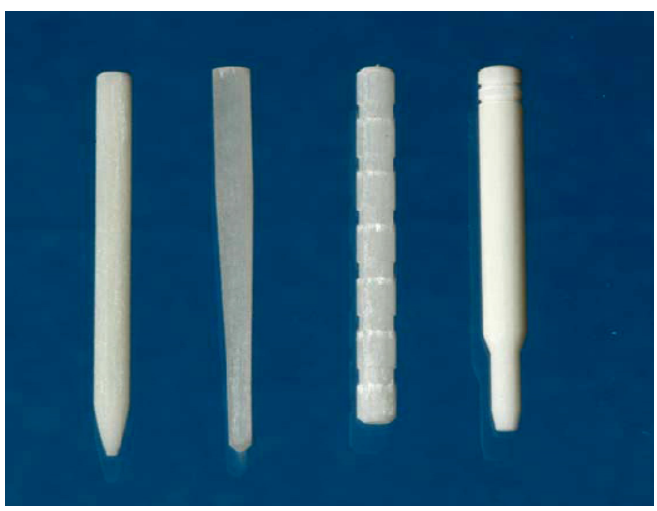

Gambar 1 Bentuk-bentuk pasak (Sumber: Hicks N. Esthetic FRC post, operative dentistry. Smile magazine: 44-8. Available from http://www. smilemag.com). fraktur yang lebih baik ${ }^{15,23-25}$ dan resistance fatigue yang lebih baik dibandingkan pasak stainless steel, titanium dan porselin. ${ }^{23-25}$

Keuntungan lain pasak fiber adalah radiopak, ${ }^{26,27}$ memiliki konduktivitas dan light transmission yang dapat mempercepat proses bonding, memiliki bentuk dan ukuran yang bervariasi, dengan empat bentuk dasar, yaitu 2-stage, tapered, paralel dan pointed (Gambar 1)

Banyak bahan sementasi yang dapat dijadikan pilihan pada penggunaan pasak fiber yang sesuai bentuk pasak, ${ }^{28}$ opasitas fiber, atau pertimbangan lain misalnya penggunaan komposit dual-cure. Alternatif pertama adalah komposit light cure, atau self-cure. ${ }^{6}$ Pada saat sementasi perlu diperhatikan beberapa hal, yaitu kontak permukaan pasak dengan resin semen, resin semen dengan bonding adesif, bonding adesif dengan dentin saluran akar serta pasak dengan core komposit. ${ }^{29-33}$

Berbagai penelitian telah dilakukan untuk meningkatkan ikatan antara permukaan pasak dengan semen resin, yaitu dengan menggunakan primer, silane, udara-abrasi, etsa dan metode lain. ${ }^{3}$

\section{PEMBAHASAN}

\section{Prosedur pelaksanaan $\mathrm{FRC}^{2,4}$}

Berikut adalah contoh penggunaan FRC pada gigi anterior. Tampak gigi 11 yang telah dirawat endodontik dan direstorasi dengan porcelain-fused to metal (PFM) menampakkan warna kehitaman, dan gigi 21 yang telah dilakukan veneering. Mahkota pada gigi 11 terlalu pendek dan kelihatan berubah warna. Gigi tidak memberikan reaksi pada perkusi serta reaksi negatif terhadap tes sensitivitas dingin (gambar 2A).

Hasil perawatan endodotik gigi 11 terlihat pada gambar 2B.Gigi 21 secara klinis dan radiologi tidak menunjukkan kelainan. Seteah informed consent, diputuskan untuk melepas mahkotagigi 11 dan pasak metal, aplikasi bahan adesif,pasak endodontik FRC, dan rencana pemasangan mahkota keramik zirkonia untuk gigi 11, dan keramik veneer untuk gigi 21.
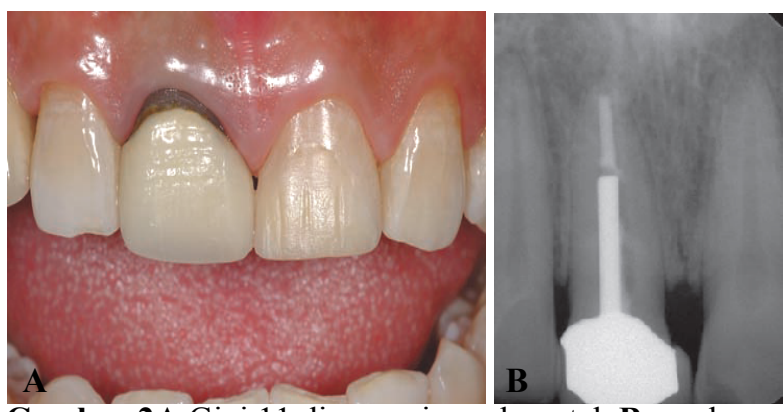

Gambar 2A Gigi 11 dipasangi pasak metal, B gambaran radiologis (Sumber: Manhart J. FRC endodontic posts. Endodont Pract 2009; 11: 24-8) 
Setelah mahkota dan restorasi gigi 11 terlepas, sisa semen pada gigi tersebut dibersihkan (gambar 3A). menggunakan energi ultrasonik dengan tujuan menghindari terjadinya fraktur akar (gambar 3B).
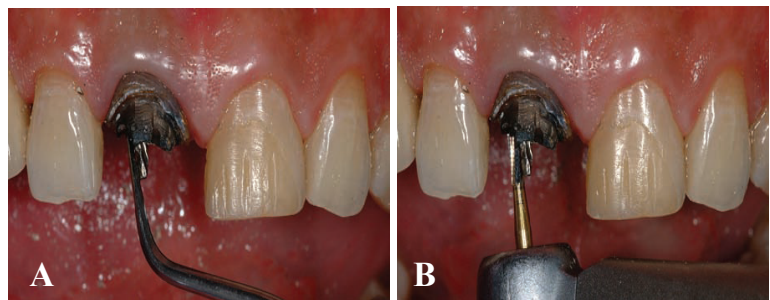

Gambar 3A mahkota telah terlepas, B membersihkan sisa semen (Sumber: Manhart J. FRC endodontic posts. Endodont Pract 2009; 11: 24-8).

Selanjutnya,saluran akar dilebarkan;kedalaman saluran disesuai panjang dan diameter pasak metal sebelumnya dan menyisakan $4 \mathrm{~mm}$ pengisian sebagai apical seal. Setelah penempatan benang retraksi, pasak FRC dengan sistem adesif (Rebilda Post, Voco) diinsersikan ke dalam kavitas. Pasak tersedia dalam tiga ukuran diameter coronal, yaitu $1,2 \mathrm{~mm}$, $1,5 \mathrm{~mm}$, dan 2,0 $\mathrm{mm}$, serta berbentuksilinder-kerucut. Bentuk taper saluran akar ditentukan dari daerah apikal dengan bentuk kerucut pasak. Hal tersebut memungkinkan adanya bentuk preparasi yang lurus dibandingkan dengan preparasi pasak berbentuk paralel (gambar 4A).

Pasak metal dibersihkan menggunakan alkohol, dikeringkan dengan udara, lalu disilanisasi (Ceramic Bond, Voco) sebagai persiapan luting. Disinfeksi menggunakan $\mathrm{NaOCl}$ 3\% kemudian dibilas dengan
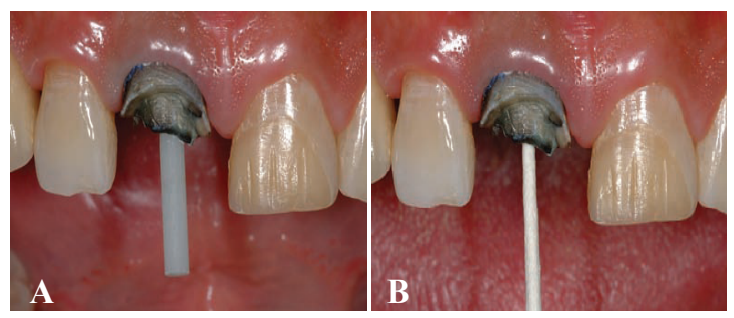

Gambar 4A Try in pasak, B saluran akar dikeringkan dengan paper point (Sumber: Manhart J. FRC endodontic posts.Endodont Pract 2009;11: 24-8).

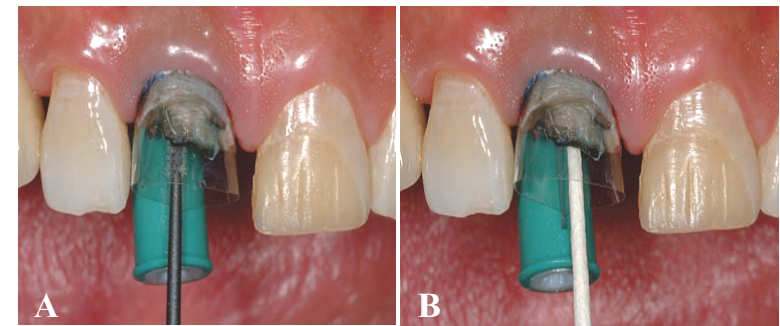

Gambar 5A Bahan adesif diulas ke dalam saluran akar, B kelebihan bahan adesif dikeringkan dengan paper point (Sumber: Manhart J. FRC endodontic posts. Endodont Pract 2009;11: 24-8).
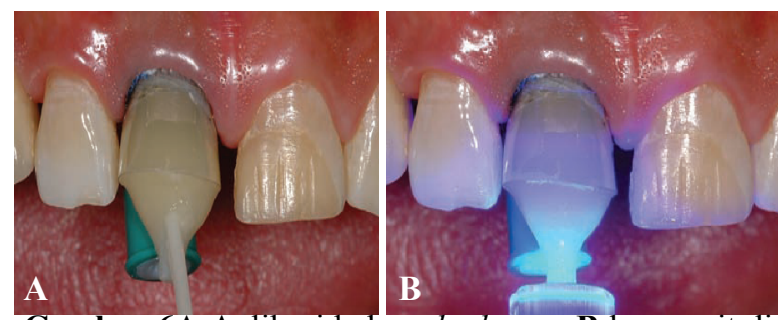

Gambar 6A Aplikasi bahan dual cure, B komposit dilight cure (Sumber: Manhart J. FRC endodontic posts. Endodont Pract 2009;11: 24-8).

air sesuai dengan instruksi pabrik, dan dikeringkan dengan paper point (gambar 4B).

Matriks kemudian dipasang untuk membentuk mahkota. Futura Bond DC (Voco), self etching, adesif dual curing kemudian diusapkan ke dalam saluran akar selama 20 detik dengan menggunakan endomicrobrush (gambar 5A),kemudian pelarutnya dikeringkan menggunakan udara bebas minyak. Kelebihan adesif dihilangkan dengan menggunakan paper point (gambar 5B).

Dual curing dengan viskositas yang rendah, Rebilda DC ditempatkan dalam QuickMix syringe (Voco), lalu komposit core-build-up ditempatkan ke dalam lubang pasak, menggunakan ujung tip aplikator, diletakkan pada tempat paling dalam dari preparasi pasak. Rebilda $D C$ diaplikasi secukupnya, lalu dengan perlahan tip ditarik keluar (gambar 6A).Komposit di-light cure selama 40 detik dengan (gambar 6B).
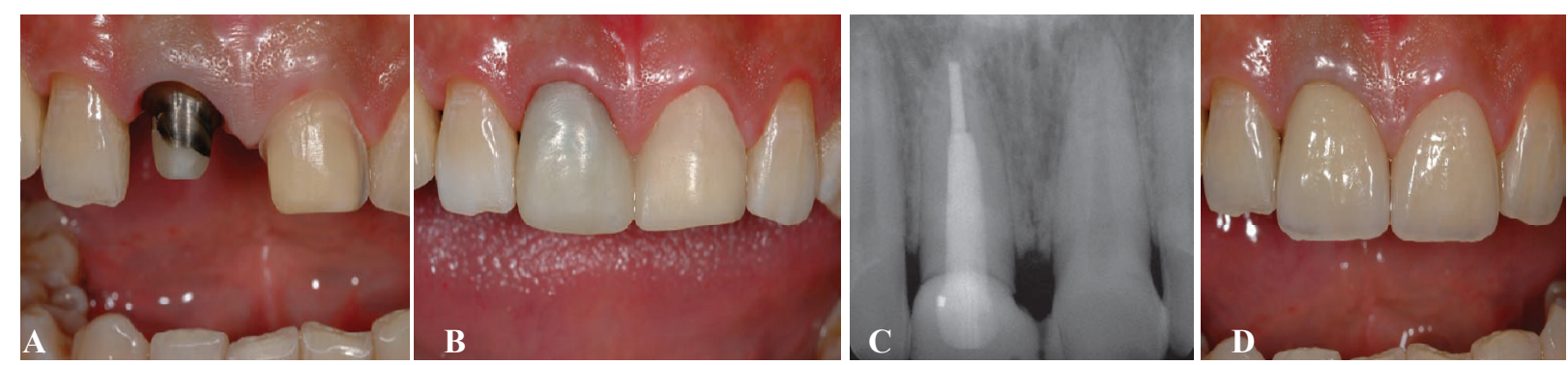

Gambar 7A Aplikasi bahan dual cure, B gigi 11 memakai mahkota sementara, C gambaran radiografi pasak pada gigi 11, D restorasi keramik zirkonia pada gigi 11 dan veneer keramik pada 21 (Sumber: Manhart J. Fiber glass reinforced composite endodontic posts. Endodont Pract 2009; 11:24-8). 
Setelah matriks diangkat, gigi 11 dipersiapkan untuk dilakukan pemasangan mahkota keramik zirkonia dan gigi 21 dipersiapkan untuk pemasangan keramik veneer (gambar 7A), dan pemasangan mahkota sementara (gambar 7B). Sementasi adesif pada pasak FRC ditempatkan terlihat jelas pada gambaran radiografi (gambar 7C). Restorasi mahkota keramik zirkonia pada gigi 11, dan veneer keramik adesif pada gigi 21 (gambar 7D).

\section{Penggunaan pasak FRC pada gigi posterior}

Gigi premolar kanan rahang atas (15) pasca endodontik, direstorasi MOD dengan amalgam, lalu mengalami fraktur pada bagian tonjol palatal setelah beberapa tahun digunakan (gambar 8A).

Meskipun garis patah terletak di bawah CEJ, pasien ingin mempertahankan gigi tersebut, dan direstorasi dengan direct $\mathrm{RBC}$ karena biaya yang lebih rendah dibandingkan dengan restorasi indirect. Jika terjadi fraktur akar, direncanakan implan dental. Setelah kondisi jaringan lunak telah sehat, dilakukan isolasi daerah cavosurface gingival margin dengan rubber dam. Restorasi amalgam lepas, tetapi tetap menjaga struktur jaringan gigi sebanyak mungkin. Selanjutnya, preparasi kavitas diselesaikan dengan tepi gingiva tidak dibevel pada permukaan aksial maupun permukaan oklusal, pembulatan sudutsudut yang tajam menggunakan bur \#2 dan bur \#4 (Brasseler, Savannah GA, AS) dan menghilangkan permukaan dentin sklerotik secara selektif (gambar 8B). Gutta percha di bukal dan palatinal dipotong 3-4 mm untuk mengekspos dentin dan meningkatkan retensi mikro bila menggunakan sistem adesif dentin email (gambar 8C).Matriks interproksimal dipasang lalu dikencangkan dengan menggunakan wedge kayu. Email dan dentin kemudian dietsa selama 30 detik menggunakan asam fosfat 34\% (gambar 8D). Selanjutnya permukaan gigi dibersihkan dari bahan etsa menggunakan semprotan air selama 30 detik dan dipertahankan tetap dalam keadaan lembab. Sistem adesif generasi kelima nano-filled acetonebased diulas pada permukaan preparasi kemudian dikeringkan dengan tekanan udara lembut (gambar 9A). Dilakukan light-cure selama 20 detik pada $800 \mathrm{~mW} / \mathrm{cm}^{2}$ dari permukaan oklusal dengan menggunakan alat curing cahaya halogen.
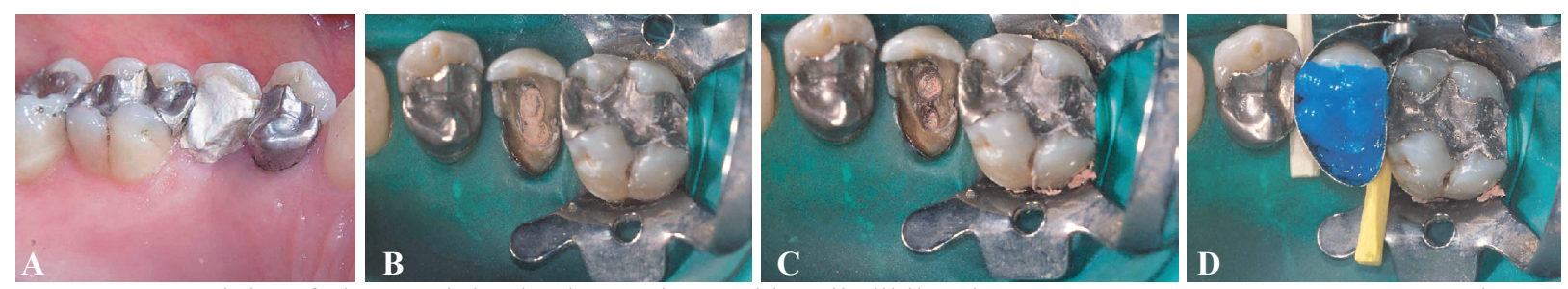

Gambar 8A Gigi 15 fraktur tonjol palatal, B Jaringan sklerotik dihilangkan, C pemotongan 3-4 mm gutta percha, D etsa asam (Sumber: Deliperi S, Bardwell DN, Coiana C. Reconstruction of devital teeth using direct fiber-reinforced composite resins: A case report. J Adhesive Dent 2005; 7(2): 1-7)
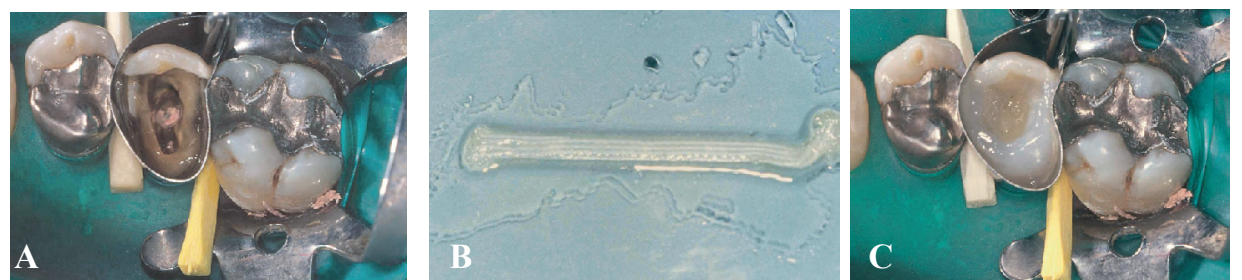

Gambar 9A Pemasangan wedge, pengulasan cairan adesif, B pasak ribbon FRC, C pemasangan pasak FRC kemudian ditutup dengan unfilled resin (Sumber: Deliperi S, Bardwell DN, Coiana C. Reconstruction of devital teeth using direct fiber-reinforced composite resins: A case report. J Adhesive Dent 2005; 7(2): 1-7).
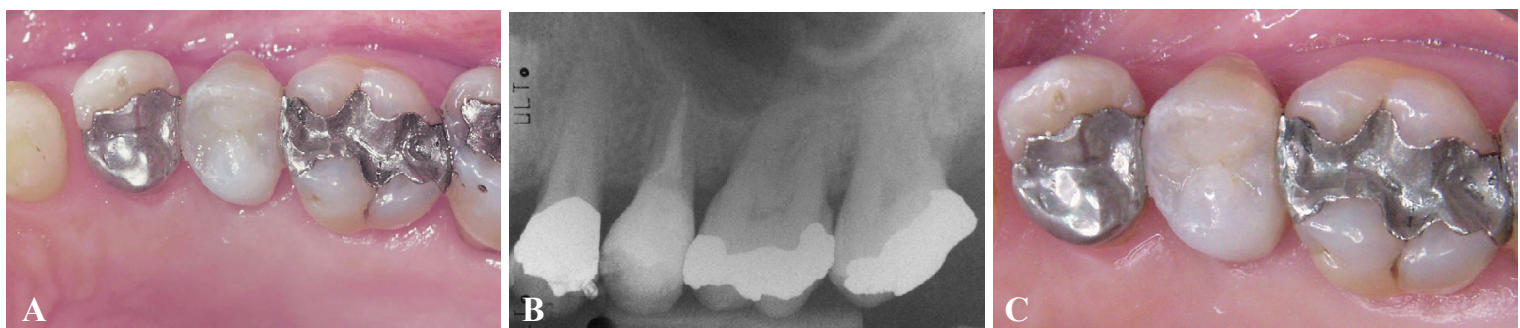

Gambar A restorasi akhir gigi 15, B gambaran radiografi 15 pasca restorasi, C klinis 15 pasca insersi (Sumber: Deliperi S, Bardwell DN, Coiana C. Reconstruction of devital teeth using direct fiber-reinforced composite resins: A case report. J Adhesive Dent 2005; 7(2): 1-7). 
Setelah penempatan pasak ribbon FRC (gambar 9B), dentin direstorasi selapis demi selapis dengan menggunakan warna B5 dan warna B3, dan layering email dilakukan membentuk konturpermukaan akhir oklusal (gambar 9C). Hasil yang memuaskan tampak dengan bentuk anatomis dan warnanya yang estetik (Gambar 10A). Gambaran radiografi gigi 15 pasca restoratif dan gambaran periodontal menunjukkan hasil yang adekuat (gambar 10B). Kepuasan penderita setelah 2 tahun pasca insersi tampak dari restorasi yang tetap adekuat (Gambar 10C).

Setelah pembahasan dan pemaparan contoh penggunaannya, disimpulkan pasak prefabricated yang terbuat dari fiber atau glass FRC mempunyai sifat biomekanik yang baik. Hal tersebut dapat meminimalkan risiko fraktur akar yang disebabkan oleh adanya tekanan yang berlebih secara terusmenerus sehingga menimbulkan tekanan pada akar gigi. Distribusi tekanan tersebut dapat diteruskan antara pasak dan dinding saluran akar serta bahan luting adesif dari pasak fiber pada saluran akar dengan semen komposit.

Pasak FRC merupakan salah satu bahan yang adekuat untuk melindungi struktur akar gigi serta menambah kekuatan dan retensi komposit. Namun penggunaan pasak fiber merupakan prosedur teknik yang sensitif. Instruksi pabrik menganjurkan untuk menggunakan kombinasi resin visible light curing unfilled, sistem self atau adesif dual curing serta semen resin untukmemastikan polimerisasi tuntas.

\section{DAFTAR PUSTAKA}

1. Deliperi S. Direct fiber-reinforced composite restoration in an endodontically-treated molar: A three-year case report. J Oper Dent 2008:209-10.

2. Manhart J. Fiberglass reinforced composite endodontic posts. Endod Pract 2009; 11: 24-8.

3. Naumann M, Metzdorf G, Fokkinga W, Watzke R. Influence of test parameters on in vitro fracture resistance of post-endodontic restorations: a structured review. J Oral Rehabil 2009: 299.

4. Deliperi S, Bardwell DN, Coiana C. Reconstruction of devital teeth using direct fiber-reinforced composite resins: a case report. J Adhesive Dent 2005; 7(2): 1-7.

5. Mateus N, Maria S, Edson A, Damiao M, Pascoal L. Removal resistance of glass-fiber and metallic cast posts with different lengths. J Oral Sci 2006; 48(1): 15-6.

6. van Wijlen P. A modified technique for direct, fibre-reinforced, resin-bonded bridges: clinical case reports. J Can Dent Assoc 2000: 1.

7. Al Heller. Rationale for low-modulus endodontic posts. Dent Today 2009; 124(2):2,3.

8. Le Bell Ronnlof AM. Fiber reinforced composites as root canal posts. Medica Odontologica 2007:15-8.

9. Hicks N. Esthetic fiber reinforced composite post. Oper Dent: 44-8 available from http://www.smile-mag.com.

10. Naumann M, Preuss A, Frankenberger R. Reinforcement effect of adhesively luted fiber reinforced composite versus titanium posts. J Dent Mater 2006; 30: 1. Available at www.sciencedirect.com.

11. Ganesh M, Tandon S. Versatility of ribbond in contemporary dental practice. Trends Biomater Artif Organs Vol 20 (1): 53-6. Available at http:www.sbaoi.org.

12. Christensen GJ. Post: Necessary or unnecessary? J Am Dent Assoc 1996; 127: 1522. Available at http://www.ada. org/prof/resources/pubs/jada/permissions.asp

13. Grandini S, Chieffi N, Cagidiaco MC, Goracci C, Ferrarri M. Fatigue resistance and structural integrity of different types of fiber posts. Dent Mater J 2008; 27(5): 691.

14. Guang-Quan Song. Three dimensional finite element stress analysis of post-core restored endodonticallly treated teeth. Manitoba: Department of Mechanical \& Industrial Engineering The University of Manitoba Winnipeg; 2005.

15. Kivanc TA, Ulusoy G. Fracture resistance of thin-walled roots restored with different post systems. Int Endodont $\mathbf{J}$ 2009; 42: 102.

16. Yuji F, Wataru K, Keiichi Y, Shiho O, Daizo O, Hiroyuki M. Effect of reinforcement with resin composite on fracture strength of structurally compromised roots. Dent Mater J 2009; 28(5): 608.

17. Abdulhamaid A. Reinforcement of fiber-reinforced composite crowns with variant margin designs. Pakistan Oral \& Dent J 2010; 30 (1): 264.

18. Takashi K, Masao Y, Shinji T, Masayuki H, Eiji K, Yutaka O. Mechanical properties of roots combined with prefabricated fiber post. Dent Mater J 2009; 28(5): 538.

19. Freilich MA, Meiers JC, Duncan JP, Goldberg AJ. Fiber reinforced composite in clinical dentistry. Chicago: Quintessence Publishing Co, Inc; 2008. p. 17-20.

20. Henrique L, Amaral M, Clovis L, Mariz G, Magne P. Composite resin reinforced with pre-tensioned glass fibers. Influence of prestressing on flexural properties. Dent Mater 2010; 26: 124.

21. Lassila LVJ, Tanner J, Maria A, Narva K, Valittu PK. Flexural properties of fiber reinforced root canal posts. Dent Mater 2004: 34-5. Available from http://intl.elsevierhealth.com/journals/dema.

22. Liviu, Steier G. Introduce new guidelines to make for easier treatment decisions in optimum restoration of missing tooth structure: linical excellence. Private Dentistry 2008; March:16. 
23. Belli S, Kont F, Eraslan O, Eskitascioglu G, Karbhart V. The effect of fiber insertion on fracture resistance of endodontically treated molars with MOD cavity and reattached fractured lingual cusps. J Biomed Mater Res 2006: 35-6. Available from http://www.interscience.wilwy.com.

24. Helvacioglu B, Alacam T, Gorgul G. Fracture resistance of premolars with one remaining cavity wall restored using different techniques. Dent Mater J 2010; 29(3): 262-3.

25. Garaoushi S, Vallitu PK, Lassila LVJ. Continuous and short fiber reinforced composite in root post-core system of severely damaged incisors. Open Dent J 2009; 3; 36-41.

26. Toman M, Toksavul S, Sankanat M, Firidinoglu F, Akin A. The evaluation of displacement resistance of glass FRC posts to root dentine using a thin slice push-out test. Int Endodont J 2009; 42: 803-4.

27. Masayuki H, Shinji T, Masao Y, Eiji K, Yutaka O. Durability of fiber-post and resin core build-up systems. Dent Mater J 2010; 29(2): 224-7.

28. Finger WJ, Ahlstrand WM, Fritz UB. Evaluation of the radiopacity of fiber-reinforced resin posts. University of Cologne and Aachen, Germany; 2010.p.1-4.

29. Monticelli F, Ferrari M, Toledano M. Cement system and surface treatment selection for fiber post luting. Med Oral Patol Oral Cir Buccal 2008; 13(3): e214-6.

30. OKeefee KL. The art and science of modern techniques for restoring badly broken down teeth. Adhesive Technol Solutions 2009; 01-02, Kuraray: 1-3

31. Bonfante G, Kaizer OB, Pegoraro LF, do Valle AL. Tensile bond strength of glass fiber posts luted with different cements. Braz Oral Restor 2007; 21(2): 159-61

32. Gracia-Godoy F, Ferrari M. Clinical trial of fiber posts luted with a self-adhesive cement. Int Dent SA 2009 ; 12 (3): 14-7

33. Bitter K, Kielbassa AM. Post-endodontic restorations with adhesively luted fiber-reinforced composite post systems:A review. Am J Dent 2007; 20 (6): 353-4. 